\title{
Combined Superior and Inferior Dermoglandular Flaps for Projection Enhancement in Gigantic Breast Amputation and Free Nipple Areola Graft
}

\author{
AYMAN ALTRAMSY, M.D.*; ABDELNASER HAMDI MOHAMMED, M.D.*; \\ MAHMOUD NASEF, M.D.* and AHMED M. NAFEH, M.D.** \\ The Department of Plastic Surgery, Faculty of Medicine, Al-Azhar* and Helwan** Universities
}

\begin{abstract}
Background: Breast amputation and free nipple areola complex (NAC) graft is reserved mainly for cases of gigantomastia. This technique usually ends by flat boxy breast without projection. Many flaps have been used to overcome the flat boxy breast. The superior and inferior flaps were used in 20 cases of gigantomastia during the period between March 2014 and October 2018. The technique, results, and complications will be presented and discussed.
\end{abstract}

The Aim of the Work: The aim of this study is to emphasize the efficacy of using combined superior and inferior flaps for projection enhancement in breast amputation and free NAC graft surgery.

Patients and Methods: A prospective study was conducted on 20 cases of gigantomastia at Al-Azhar University Hospitals. The classic breast amputation was done in conjunction with elevation of superior and inferior flaps. The average dimensions of the flaps were $8 \times 13 \mathrm{~cm}$. The free ends of both flaps were sutured together and fixed to the pectoral fascia by sutures at the upper part of the breast. The procedure was completed as a wise pattern technique and ended by an inverted T scar. All patients were followed-up for a period of 6 months.

Results: Regarding projection enhancement which is the main target of this study, all cases showed increases projection that ranged from excellent in 14 cases $(70 \%)$ to good in 6 cases $(30 \%)$ according tothe designed questionnaire.

Conclusion: Adding superior and inferior dermoglandular flaps in breast amputation and free NAC graft enhances breast projection, decreases the boxy appearance and bottoming out rate of breast.

Key Words: Gigantomastia - Free nipple-areola graft Combined superior - Inferior flaps.

\section{INTRODUCTION}

Gigantomastia is a pathological condition in which, the breast weight exceeds $3 \%$ of the total body weight or when the excised breast tissue is more than $1.5 \mathrm{~kg}$ per breast $[\mathbf{1 , 2}]$.

Secondary to the increase in volume and weight of the breasts, stretching of the skin and breast support system (Cooper's ligaments) occurs leading to breast ptosis [3].

Many techniques were described for correction of gigantomastia $[\mathbf{4 , 5 , 6}$. Reduction amputation mammaplasty with free nipple-areola grafting is reserved for patients complaining of gigantomastia and severe ptosis (the distance between the nipple and the inframammary fold exceeds $25 \mathrm{~cm}[7,8]$.

The aim of that procedure is to relieve pain and discomfort associated with excessive hypertrophy of breast tissue and to achieve acceptable breast size and shape. The main disadvantage of that procedure is the flat boxy breast with poor projection. Many flaps have been used to overcome this disadvantage which include superior, inferior, medial, superomedial and lateral based flaps combined with wise-pattern skin excision $[\mathbf{9 , 1 0 , 1 1 ]}$.

In the present study, superior and inferior dermoglandular flaps with a dimension less than the classic long bipedicle flap were used to achieve breast projection in gigantic breast amputation and free nipple areola grafting.

\section{PATIENTS AND METHODS}

Between March 2014 and October 2018, twenty patients with gigantic breasts were included in this prospective study. All patients underwent 
reduction amputation mammaplasty with free nipple areola grafting at Al-Azhar University Hospitals. Their ages ranged between 25 and 48 years with a mean age of (36.1). All patients were married and non-smokers. Preoperative evaluation included clinical examination and routine laboratory investigations. Soft tissue mammography was done for 11 cases above the age of 35 years and ultrasonic breast examination for 9 patients under the ages of 35 years to rule out the possibility of breast masses.

An informed consent was signed from all cases under the study after discussing the possibilities of partial or complete NAC graft loss, NAC hypopigmentation or loss of sensation and failure of futured breast feeding.

Standardized digital photographs were taken preoperatively; frontal, right and left lateral, right and left oblique views for each patient.

\section{Preoperative markings:}

With the patient in the standing position, detailed measurements were obtained and documented. The anterior midline, breast meridian and the inframammary crease were marked. The new nipple position was marked $21-23 \mathrm{~cm}$ from the suprasternal notch or at the level of the inframammary fold. The areola was reduced to a diameter of $4-4.5 \mathrm{~cm}$ and marked. The Tangent line (the chest circumference over the breast at the level of the inframammary fold) was measured and recorded in each case pre-operatively.

The keyhole wise pattern was marked with the length of each limb about $8 \mathrm{~cm}$ and the angle was tailored according to size of the breast. The superior and inferior flaps were marked on the axis of the breast meridian. The average dimension of these flaps was $8 \times 13 \mathrm{~cm}$ (Fig. 1).

\section{Operative technique:}

With the patients in supine position, the superior and inferior flaps were de-epithelialized. Nippleareola complex was harvested and kept in normal saline solution (Fig. 2A).

Incisions were done along the marked borders of the superior and inferior flaps and raised with thickness about 1.5 to 2 inches. The breast tissues within the boundary of the keyhole were excised down to pectoral fascia (Fig. 2B).

Both flaps were sutured together at their free borders by $3 / 0$ vicryl sutures then fixed to the pectoral fascia at the level of the $4^{\text {th }}$ rib by $3 / 0$ prolene sutures to create maximum superomedial projection and minimize flap ptosis and bottoming out (Fig. 2C).

The procedure was completed as wise pattern technique. The folded flaps were then covered by the medial and lateral breast wings.

With the patient in 45-degree, symmetry was assessed. Finally, the free nipple-areola grafts were sutured at its new position on the superior flap and fixed using tie-over. Good hemostasis, suction drains and finally skin closure was done in twolayers.

The weight of the resected parts was documented (Fig. 2D). All patients were followed-up for a period of 6 months postoperatively (Fig. 3A,B).
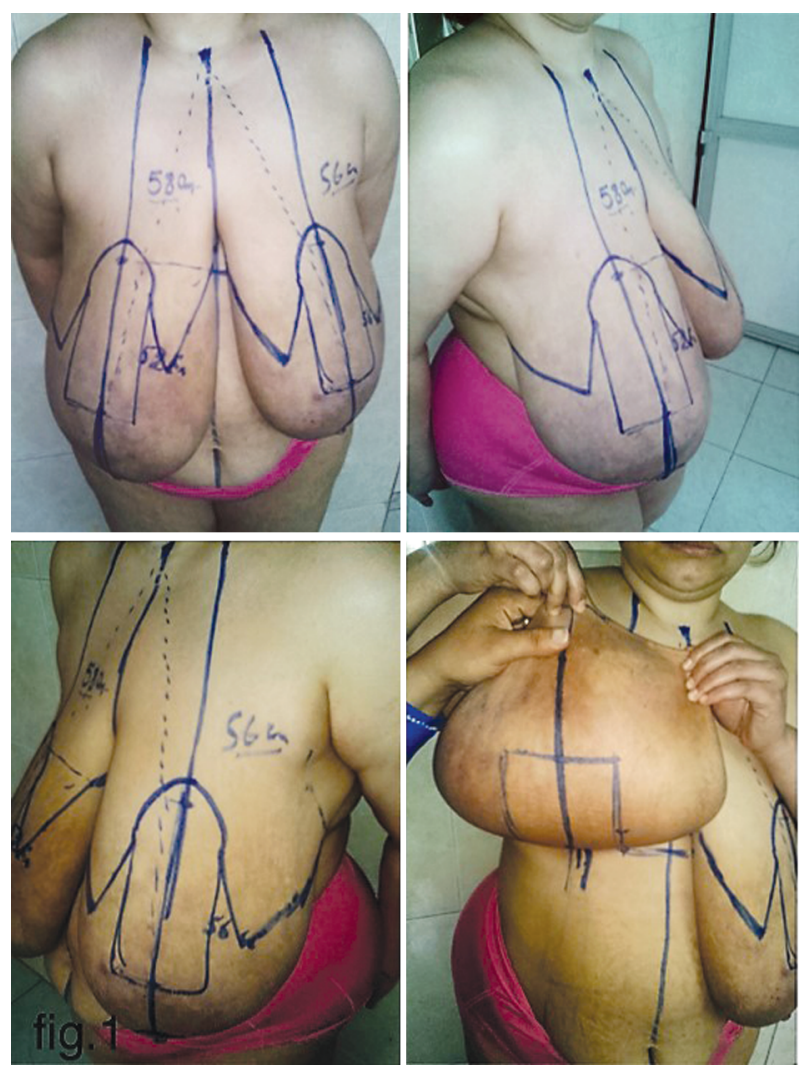

Fig. (1): Pre-operative photo: Marking of the superior and inferior flaps. 

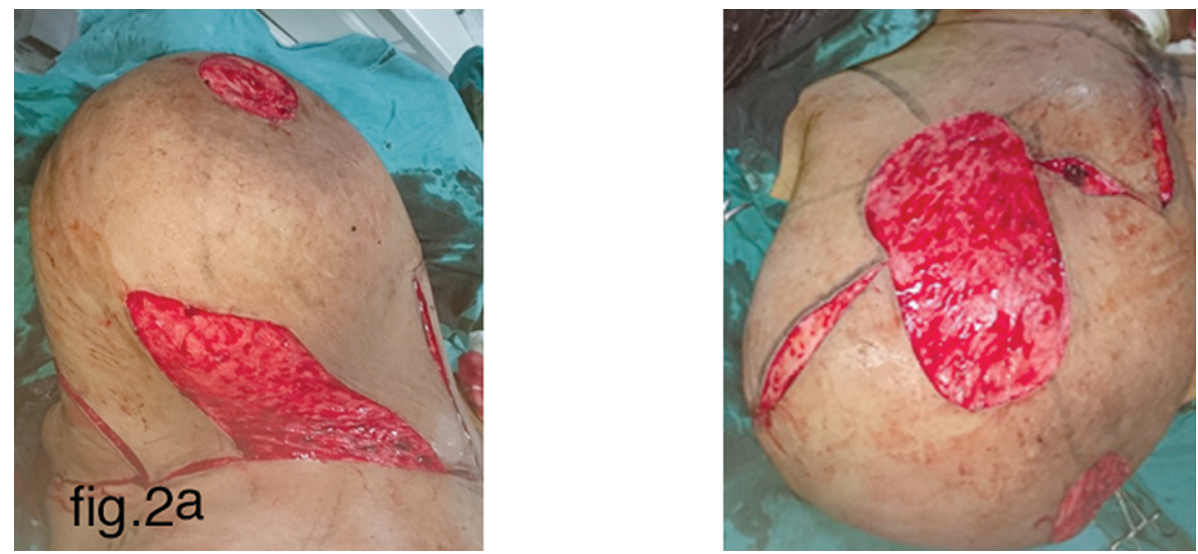

Fig. (2A): De-epithelialization of the Superior flap (Right), and de-epithelialization of inferior flap with harvesting of the NAC (Left).
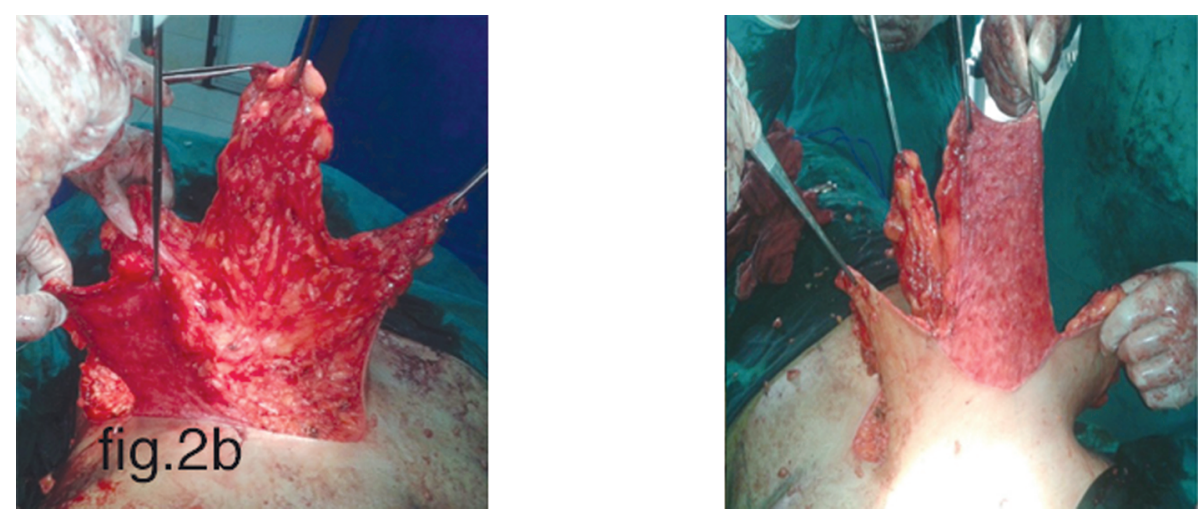

Fig. (2B): Intraoperative photo: Raising of the Superior and inferior dermoglandular flaps.
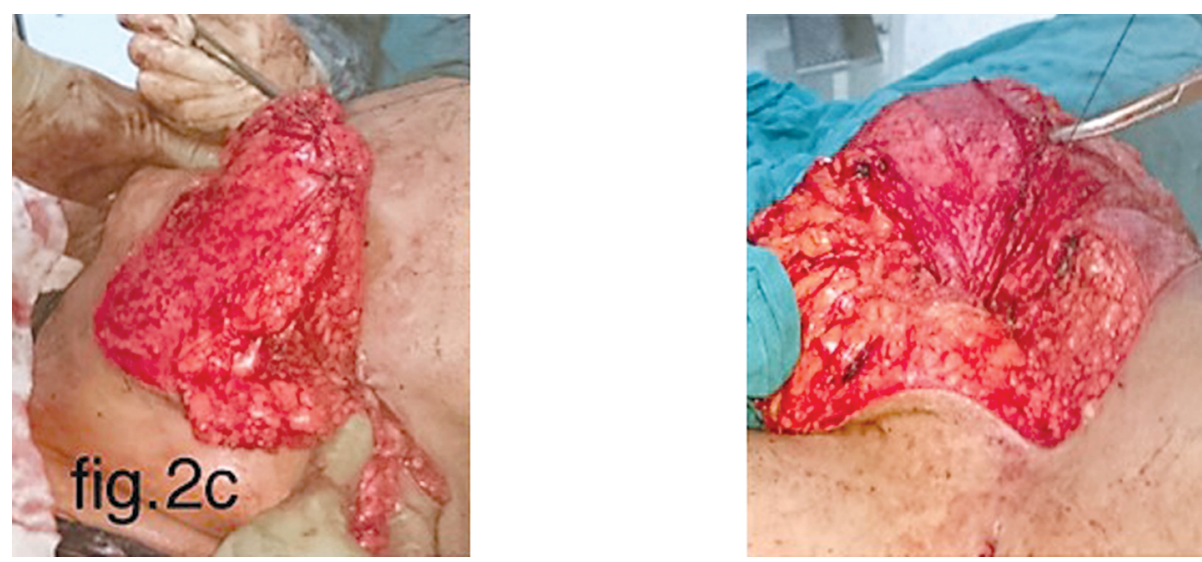

Fig. (2C): Intraoperative photo: Suturing of both flaps at their free ends (Left); and fixation to the pectoral fascia (Right).
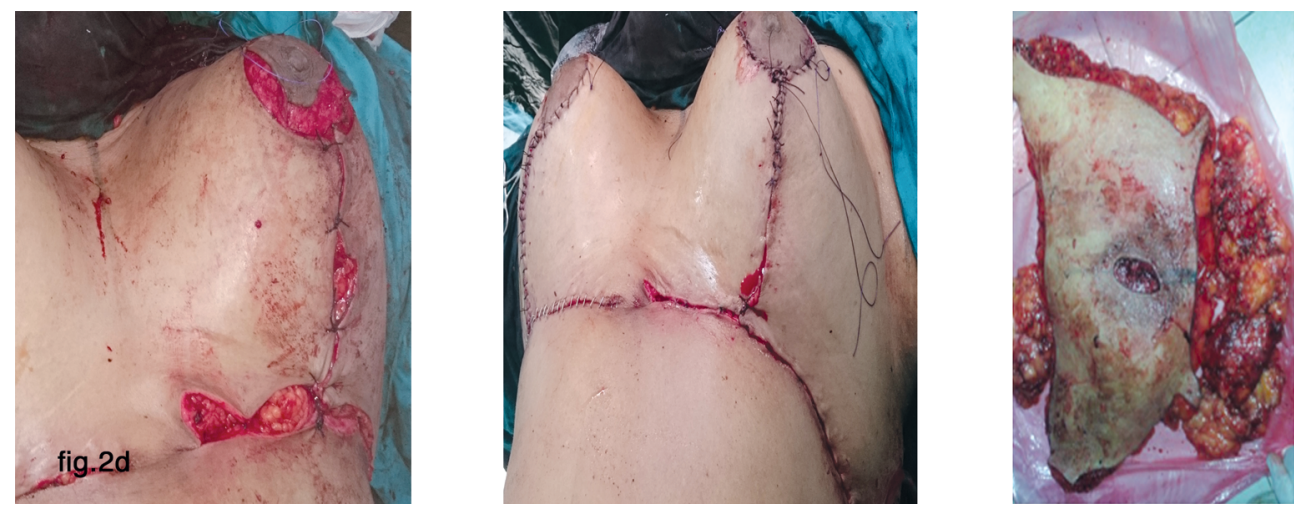

Fig. (2D): Intraoperative photo: Tailoring the skin envelope over flaps (Left), transplanting of the NAC graft over the base of the superior flap (Middle), and the excised breast tissue (Right). 

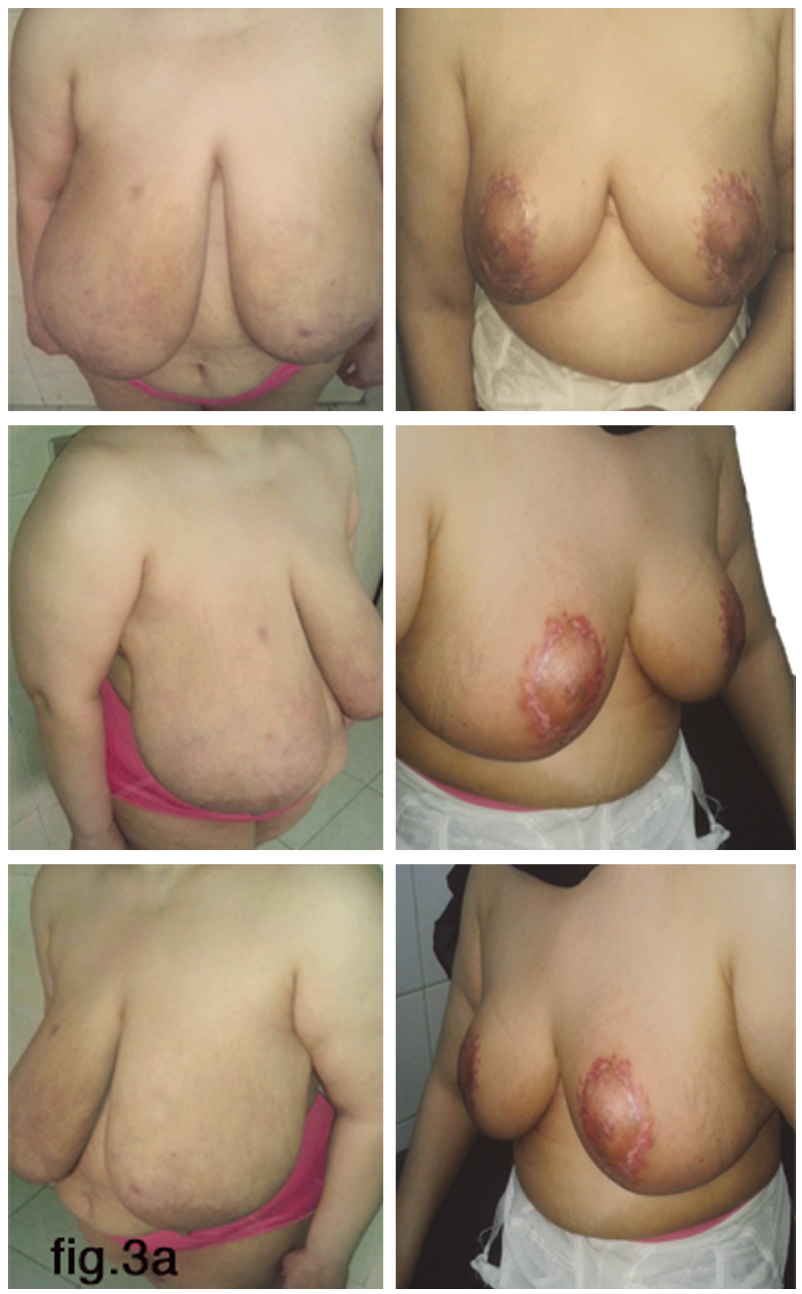

Fig. (3A): Case 11- Pre and postoperative views (frontal and lateral views).

\section{RESULTS}

Twenty patients were included in this study. Their ages ranged from 25-48 years with the mean age (36.1). The distance from the suprasternal notch to the nipple was $50-60 \mathrm{~cm}$ with the mean $(55.2 \mathrm{~cm})$. The excised tissue from both breasts was ranged from $(4100 \mathrm{~g})$ to $(4750 \mathrm{~g})$ with the mean (4334g).

Postoperative results were evaluated subjectively through the designed patient questionnaire and objectively through chest circumference at the Tangent line.

\section{1- Patient questionnaire:}

We designed questionnaire that include 5 items regarding size, symmetry, breast projection, NAC position, and the final scar. For each item, a score ranged from 1-4 according to the patient satisfac-
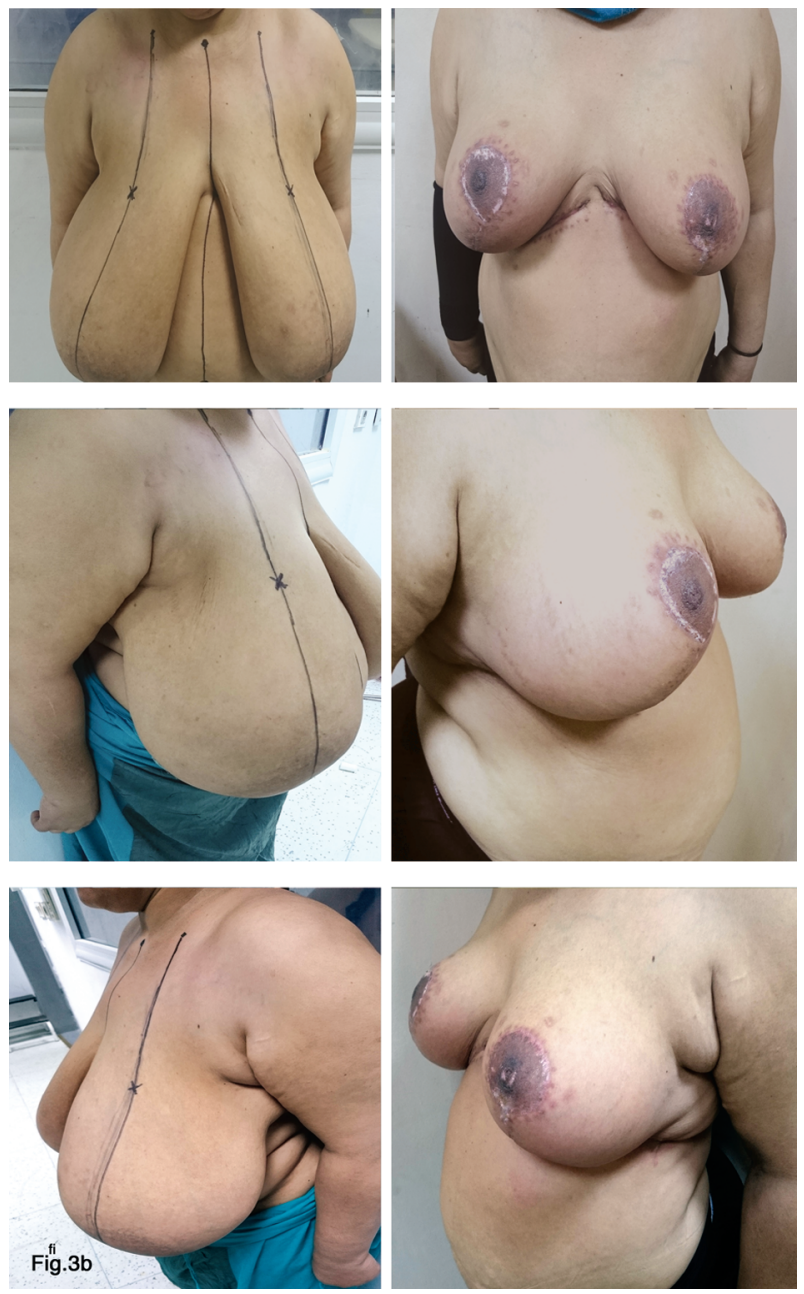

Fig. (3B): Case 16: Pre and postoperative views (frontal and lateral wiews).

tion. The scores were summated from each questionnaire and graded as excellent (17-20), good (14-16), fair (10-13), and poor result (5-9) as shown in Table (1).

According to the subjective patient satisfaction questionnaire, 14 cases (70\%) were excellent and 6 cases $(30 \%)$ were good.

\section{2- Objective assessment:}

We choose the Tangent line as a reference line for assessment of the gained projection in both breasts through the difference between the preand post-operative measures. Preoperatively, the chest circumference was ranged from 102 to 123 $\mathrm{cm}$ with a mean of $(111.5 \mathrm{~cm})$ and postoperatively, it was ranged from 116 to $136 \mathrm{~cm}$ with a mean of $(125.7 \mathrm{~cm})$. The gained projection in each breast was ranged from 6 to $8 \mathrm{~cm}$ with a mean of $(7.1 \mathrm{~cm})$ as shown in Table (2). 
The operative time was ranged from 3 hours to 3 hours and 40 minutes with a mean of (3.15h).

Major complications had not occurred in any case under the study such as hematoma, wound dehiscence or total loss of the NAC.

Partial NAC graft failure had occurred in two cases $(10 \%)$ case no. 1 and 13 that was managed conservatively and ended by patchy hypopigmentation.
Two cases (10\%) case no. 7 and 14 developed hypertrophic scarring at the inframammary line, and they advised to use silicone gel. Two cases (10\%) case no. (6 and 9) exhibited small cystic mass which was diagnosed by ultrasonography as fat necrosis and advised to follow-up.

Single case $(5 \%)$, case no. 8 , had developed bottoming out of her breasts. Dog-ear deformity was shown in single case $(5 \%)$; case no. 8 . The complications were summarized in Table (3).

Table (1): Patient questionnaire.

\begin{tabular}{lccccccc}
\hline No. & Breast size & Projection & NAC position & Symmetry & Scar & Score & Degree \\
\hline 1 & 4 & 4 & 3 & 4 & 2 & 17 & Excellent \\
2 & 4 & 3 & 4 & 4 & 3 & 18 & Excellent \\
3 & 4 & 4 & 3 & 4 & 3 & 18 & Excellent \\
4 & 4 & 3 & 3 & 4 & 2 & 16 & Good \\
5 & 3 & 4 & 3 & 4 & 3 & 17 & Excellent \\
6 & 3 & 4 & 4 & 4 & 3 & 18 & Excellent \\
7 & 4 & 4 & 3 & 3 & 3 & 17 & Excellent \\
8 & 3 & 4 & 3 & 4 & 3 & 17 & Excellent \\
9 & 3 & 4 & 3 & 3 & 3 & 16 & Good \\
10 & 3 & 4 & 3 & 4 & 3 & 17 & Excellent \\
11 & 2 & 4 & 4 & 2 & 3 & 15 & Good \\
12 & 4 & 3 & 4 & 4 & 3 & 18 & Excellent \\
13 & 3 & 4 & 3 & 4 & 3 & 17 & Excellent \\
14 & 3 & 3 & 3 & 4 & 3 & 16 & Good \\
15 & 4 & 3 & 4 & 4 & 3 & 18 & Excellent \\
16 & 3 & 3 & 4 & 4 & 2 & 16 & Good \\
17 & 3 & 4 & 3 & 4 & 3 & 15 & Excellent \\
18 & 4 & 3 & 4 & 4 & 2 & 17 & Excellent \\
19 & 3 & 3 & 3 & 4 & 2 & 16 & Good \\
20 & 4 & 3 & & 4 & 3 & 17 & Excellent \\
\hline
\end{tabular}

Table (2): Pre and postoperative data collection.

\begin{tabular}{|c|c|c|c|c|c|c|c|c|}
\hline Case & Age & $\begin{array}{c}\text { Pre-op. } \\
\text { NAC from } \\
\text { suprasternal } \\
\text { notch }(\mathrm{cm})\end{array}$ & $\begin{array}{c}\text { Post-op } \\
\text { NAC from } \\
\text { suprasternal } \\
\text { notch }(\mathrm{cm})\end{array}$ & $\begin{array}{c}\text { Preop. } \\
\text { Chest circumference } \\
\text { at the tangent } \\
\text { line }(\mathrm{cm})\end{array}$ & $\begin{array}{c}\text { Postop. } \\
\text { Chest circumference } \\
\text { at the tangent } \\
\text { line }(\mathrm{cm})\end{array}$ & $\begin{array}{l}\text { Average } \\
\text { gained } \\
\text { Projection/ } \\
\text { Breast }(\mathrm{cm})\end{array}$ & $\begin{array}{l}\text { Weight of } \\
\text { excised breast } \\
\text { tissue }(\mathrm{gm})\end{array}$ & $\begin{array}{l}\text { Operative } \\
\text { Time } \\
\text { (hour) }\end{array}$ \\
\hline 1 & 25 & 55 & 23 & 105 & 118 & 6.5 & 4150 & 3.00 \\
\hline 2 & 27 & 56 & 23 & 115 & 131 & 8 & 4300 & 3.00 \\
\hline 3 & 35 & 54 & 21 & 114 & 130 & 8 & 4200 & 3.00 \\
\hline 4 & 35 & 54 & 21 & 110 & 124 & 7 & 4250 & 3.15 \\
\hline 5 & 36 & 54 & 23 & 109 & 123 & 7 & 4250 & 3.10 \\
\hline 6 & 38 & 57 & 23 & 120 & 133 & 6.5 & 4550 & 3.15 \\
\hline 7 & 40 & 60 & 22 & 118 & 132 & 7 & 4400 & 3.40 \\
\hline 8 & 42 & 58 & 23 & 123 & 136 & 6.5 & 4750 & 3.30 \\
\hline 9 & 40 & 54 & 23 & 106 & 121 & 7.5 & 4150 & 3.10 \\
\hline 10 & 33 & 54 & 22 & 116 & 129 & 6.5 & 4350 & 3.15 \\
\hline 11 & 34 & 55 & 23 & 118 & 133 & 7.5 & 4525 & 3.20 \\
\hline 12 & 38 & 55 & 22 & 115 & 131 & 8 & 4450 & 3.30 \\
\hline 13 & 32 & 56 & 23 & 115 & 129 & 7 & 4450 & 3.25 \\
\hline 14 & 41 & 55 & 23 & 113 & 128 & 7.5 & 4450 & 3.15 \\
\hline 15 & 48 & 54 & 22 & 102 & 116 & 7 & 4100 & 3.00 \\
\hline 16 & 41 & 51 & 23 & 104 & 119 & 7.5 & 4200 & 3.20 \\
\hline 17 & 39 & 50 & 23 & 106 & 121 & 7.5 & 4250 & 3.00 \\
\hline 18 & 40 & 52 & 22 & 108 & 122 & 7 & 4400 & 3.00 \\
\hline 19 & 40 & 51 & 23 & 108 & 121 & 6.5 & 4300 & 3.40 \\
\hline 20 & 41 & 52 & 23 & 105 & 117 & 6 & 4200 & 3.20 \\
\hline
\end{tabular}


Table (3): Complications.

\begin{tabular}{ll}
\hline Complications & $\mathrm{n}(\%)$ \\
\hline Infection & $0(0)$ \\
Wound breakdown & $0(0)$ \\
Hematoma & $0(0)$ \\
Seroma & $0(0)$ \\
Hypertrophic scar & $2(10)$ \\
fat necrosis & $2(10)$ \\
Dog-ear deformity & $1(5)$ \\
Partial nipple areola graft failure & $2(10)$ \\
Nipple areola graft loss & $0(0)$ \\
Nipple and areola hypopigmentation & $2(10)$ \\
Bottom-out deformity & $1(5)$ \\
\hline
\end{tabular}

\section{DISCUSSION}

Creating an aesthetically shaped breast in a patient with gigantomastia is a challenging job because of the Poor projection which is a very common complaint encountered by the surgeons [12].

Many dermoglandular flap techniques have been suggested as superior, inferior, medial and lateral based flaps with various thickness and dimensions for correction of gigantomastia but the ideal remains controversial [13].

Many projection enhancement modifications have been shown in literatures as mentioned before but how the results of these techniques were assessed? In general, nearly all the authors preferred photographic evaluation to assess the obtained projection $[\mathbf{1 4 , 1 5}]$.

Gorgu et al., and Koger et al., were concluded the effectiveness of using inferior pedicle with free nipple areola complex for enhancement of breast projection $[\mathbf{1 6 , 1 7 ]}$.

Romano et al., and Misirlioglu and Akoz used the superior dermoglandular flaps, to increase the central projection [18].

A superolateral dermoparenchymal flap has been recruited by Strauch et al., in which the flap is rotated upwards after fashioning it to create a "periwinkle effect" by circular rotation to increase projection from chest wall and create a more rounded contour [19].

Vertical pedicle flaps are also greatly used to increase breast projection. Abramson de-epithelializes the superior pedicle between the two vertical limbs of the wise template and also maintained an inferior dermal pedicle extending halfway between the inframammary fold and nipple. The inferior flap is sutured to the pectoral fascia and the superior flap is the folded over it and finally covered by the lateral and medial flaps [20].

There are common concerns in considering grafting over NAC transposition in gigantomastia such as pedicle length, pedicle folding and kinking of the pedicle, that affect blood supply to the NAC [21].

In the present study we recruited the superior and inferior dermoglandular flaps with $13 \mathrm{~cm}$ length and $8 \mathrm{~cm}$ width to provide a central mound to the breast. The thickness of the flap increases gradually towards the pedicle base to preserve more perforators supplying the flaps.

The superior and inferior flaps were sutured together at its free ends with vicryl sutures aiming to increase the flap length without fear of distal hypoperfusion. The flap was folded on itself and fixed to the pectoral fascia by prolene sutures to decrease the chance of bottoming out of the breast.

The combined superior and inferior pedicle flaps provide many advantages; first, allow more glandular excision from the lateral, medial and central areas of the breast with more preservation of pedicled tissue. Second, alleviates the possibility of distal fat necrosis that occurred with single long pedicle techniques and finally low incidence of free nipple areola graft loss as the bed is well perfused.

The higher rate of satisfaction in our cases could be explained by the total disappearance of the heavy breast weight with its sequelae which was the main target for surgery in our cases. The majority of cases were happy with their new ordinary breast shape in spite of scars and any other minor defaults.

Conclusion: Adding superior and inferior dermoglandular pedicle flaps to breast amputation and free NAC graft in patients with gigantomastia can significantly provide satisfactory breast shape regarding projection and volume by augmenting the overlapped superior and inferior pedicle flaps. Fixing the overlapped flaps to the pectoral fascia decreases the rate of bottoming out and provides longtime results.

Declaration of conflict of interest: Authors have nothing to disclose.

Ethical approval: The procedure was done in accordance with the ethical standards of Faculty of Medicine, Al-Azhar University. 
Informed consent: Written informed consent was obtained from all cases under the study with special concerns regarding the possibility of partial or complete NAC graft loss, hypopigmentation, loss of sensation in NAC graft, and loss of future breast feeding.

\section{REFERENCES}

1- Dafydd H., Roehl K.R., Phillip S., et al.: Redefining gigantomastia. Journal of Plastic, Reconstructive \& Aesthetic Surgery, 64 (2): 160, 2011.

2- Fatma B., Alper Ural and Mehmet Bekerecioğlu: Inferior and Central Mound Pedicle Breast Reduction in Gigantomastia: A Safe Alternative? Journal of Investigative Surgery. Published online: 12 Aug., 2019.

3- Syed A. Hoda, Edi Brogi, Fred Koerner, et al.: Rosen's Breast Pathology. Wolters Kluwer Health, pp. 152. -ISBN 978-1-4698-7070-0, 2014.

4- Mehmet C., Selcuk A., Burak E., et al.: Management of Gigantomastia: Outcomes of Superomedial Pedicle with Vertical Scar or Wise Pattern Skin Excision. World J. Plast. Surg. May, 6 (2): 206-211, 2017.

5- Melody F., Pius A., Paa E., et al.: Combining Breast Reduction Techniques to Treat Gigantomastia in Ghana. Plast Reconstr. Surg. Glob Open. Feb., 6 (2): e1673, 2018.

6- Alaa Gheita: Mammaplasty: The "Super Flap" or the Superior Pedicle Extra Long Flap for Massive Breasts with Marked Ptosis or Gigantomastia. Aesth. Plast. Surg., 33: 461-470, 2009 .

7- Andrea Y. Lo, Roy P. Yu, Anjali Raghuram, et al.: Patient Characteristics Associated with Free Nipple Graft Reduction Mammoplasty. Cureus. Jul., 12 (7): e9063, 2020.

8- Al-Shaham AA.: Pedicle viability as the determinant factor for conversion to free nipple graft. Can J. Plast. Surg. Spring, 18 (1): e1-e4, 2010.

9- Akmal H., Marzida A. and Normala B.: Juvenile Breast Hypertrophy: A Successful Breast Reduction of $14.9 \%$ Body Weight without Recurrence in a 5-Year Follow-Up. Case Rep. Surg., 3491012, 2017.

10- Basaran K., Ucar A., Guven E., et al.: Ultrasonographically determined pedicled breast reduction in severe gigantomastia. Plast. Reconstr. Surg., 128: 252e-259e, 2011.
11- Van Wingerden J.J.: Avoiding free nipple grafting in gigantomastia with the inferior pedicle technique. Ann. Plast. Surg., 56: 465-467, 2006.

12- Bauermeister A.J., Gill K., Zuriarrain A., Earle S.A., et al.: Reduction mammaplasty with superomedial pedicle technique: A literature review and retrospective analysis of 938 consecutive breast reductions. J. Plast. Reconstr. Aesthet. Surg., 72 (3): 410-418, 2019.

13- Guven E., Aydin H., Basaran K., et al.: Reduction mammaplasty using bipedicled dermoglandular flaps and freenipple transplantation. Aesthet. Plast. Surg., 34: 738-744, 2010.

14- Karsidag S., Akcal A., Karsidag T., et al.: Reduction mammaplasty using the free-nipple graft vertical technique for severe breast hypertrophy: Improved outcomes with the superior dermoglandular flap. Aesthet. Plast. Surg., 35: 254-261, 2011

15- Karaca Basaran, Funda Akoz Saydam, Idris Ersin, et al.: The Free-Nipple Breast-Reduction Technique Performed with Transfer of the Nipple-Areola Complex over the Superior or Superomedial Pedicles. Aesth. Plast. Surg., 38: 718-726, 2014.

16- Gorgu M., Ayhan M., Aytug Z., et al.: Maximizing breast projection with combined free nipple graft reduction mammaplasty and back-folded dermoglandular inferior pedicle. Breast J., 13: 226-232, 2007.

17- Koger K.E., Sunde D., Press B.H., et al.: Reduction mammaplasty for gigantomastia using inferiorly based pedicle and free-nipple transplantation. Ann. Plast. Surg., 33: 561-564, 1994.

18- Misirlioglu A. and Akoz T.: Familial severe gigantomastia and reduction with the free-nipple graft vertical mammoplasty technique: Report of two cases. Aesthet. Plast. Surg., 29: 205-209, 2005.

19- Strauch B., Elkowitz M., Baum T., et al.: Superolateral pedicle for breast surgery: An operation for all reasons. Plast. Reconstr. Surg., 115 (5): 1269-1277, 2005.

20- Abramson D.L.: Increasing projection in patients undergoing free nipple graft reduction mammoplasty. Aesthetic Plast. Surg., 23 (4): 282-284, 1999.

21- Jackson I.T., Bayramicli M., Gupta M., et al.: Importance of the pedicle length measurement in reduction mammoplasty. Plast. Reconstr. Surg., 104 (2): 398-400, 1999. 